\title{
Early Life Effects on Aging
}

\author{
Avan Aihie Sayer and Cyrus Cooper
}

MRC Environmental Epidemiology Unit, University of Southampton, Southampton General Hospital, Southampton, UK

\section{Introduction}

It is becoming increasingly apparent that the early environment both before birth and in infancy has profound effects on aging and long-term health. This is due to environmental programming whereby influences acting at critical periods of growth and development can permanently change structure and function with lifelong consequences. Many biological characteristics of the adult can be affected including the maximum size attained, the structure and function of different systems and the response to stimuli [1]. Nutrition is the most widely researched cause of environmental programming but other agents include physical factors such as temperature, light and noise.

\section{Early Environment and Long-Term Effects}

Animal evidence to support environmental programming is extensive. Perhaps one of the most dramatic examples is that which occurs in the American alligator where egg incubation temperature has been shown to determine sex [2]. If the eggs are incubated at $30{ }^{\circ} \mathrm{C}$, all the offspring are female. If incubated at $33^{\circ} \mathrm{C}$ all the offspring are male. At temperatures between 30 and $33^{\circ} \mathrm{C}$, there are varying proportions of females and males. It is believed that the fundamental sex is female, and a transcription factor is required to divert growth along a male pathway. Instead of being controlled genetically by a sex chromosome, the transcription factor depends on the environment, specifically temperature. Adult vision has been shown to be influenced by early visual experience, for example unilateral deprivation of vision after birth can result in permanently reduced visual acuity in that eye [3]. This phenomenon has been described in man as well as in a number 
of animal species. Hearing appears to be vulnerable to noise exposure in utero. For example an increase in the risk of suffering hearing loss at high frequencies has been reported for children whose mothers were exposed to high levels of noise during pregnancy [4] and prolonged noise exposure in pregnant sheep produces lambs with greater histological changes in their cochleae [5]. There is evidence that a number of species undergo a period of heightened susceptibility to noise during development [6] and the timing of the critical period varies according to species. It has been suggested that the critical period coincides best with maturation and innervation of the hair cells in the cochlea [7]. The most extensively researched cause of environmental programming, however, is nutrition and its effects on a number of long-term outcomes are well documented.

\section{Nutritional Programming}

Fetal nutrition is the major regulator of fetal growth in late gestation and undernutrition at this stage has the immediate outcome of reduced growth [8]. Size at birth is determined primarily by the maternal uterine environment rather than parental genotype as evidenced by cross breeding and embryo transplant experiments in a variety of species [9] and small size at birth is seen with inadequate fetal nutrition. However there is an indirect relationship between fetal nutrition and maternal nutrition due to the existence of the maternal fetal supply line which includes maternal diet, maternal metabolism and endocrine status, uterine and umbilical blood flows and placental transfer capacity and metabolism. Fetal growth, fetal nutrition and maternal nutrition have all been investigated in relation to adverse longterm sequelae. Temporary undernutrition in early life may be associated not only with immediate reduced growth but also a permanent reduction in size [10]. Historical human population studies have shown that adult height is reduced following limited food availability in early life [11]. Paradoxically, early starvation may also be followed by adult obesity. Men exposed to famine in early gestation during the Dutch Hunger Winter of 1944-1945 became obese adults [12], possibly related to the setting of hypothalamic control of appetite in relation to body size in early gestation [13].

The effect of inadequate prenatal nutrition on the development and growth of different body systems has also been addressed. The endocrine system has been of particular interest as nutritional influences on fetal growth may be mediated by nutritional regulation of fetal endocrine status. The major hormones regulating fetal growth in late gestation are insulin and insulin-like growth factors (IGFs) [14]. In the rat, a low-protein diet during pregnancy reduces the $\mathrm{B}$ cell mass and reduces islet cell vascularisation of the offspring [15] with long-term effects on insulin and glucose levels [16]. Nutritional programming of specific organs has been studied. There is evidence 
that brain growth and long-term function are affected by feeding in early life [17]. Another study showed improved visual function in children who had been breast rather than bottle fed [18]. Animal work has demonstrated that a prenatal low-protein diet may be followed by alterations in the growth plate of long bones, emphysematous changes in the lung [19], small kidneys [20], raised blood pressure [21] and fewer, less well-differentiated villi in the intestine [22].

\section{Preweaning Diet Restriction and Aging}

It is not in question that aging can be altered by nutritional intervention. The well-documented beneficial effects of postweaning diet restriction on aging include prolongation of lifespan, reduced incidence of a number of age-related diseases, and the attenuation of structural and functional changes associated with age. However the effects of diet restriction prior to weaning, both in utero and immediately after birth, have been little studied [23]. The few existing studies suggest that preweaning restriction of diet has an opposite effect. Early work focused on age-related changes. One study showed that maternal diet restriction resulted in progeny with permanent stunting of growth, anaemia and reduced resistance to hypothermia [24] and another demonstrated earlier age-related haemoglobin decline in the offspring [25]. Further research showed that a reduction of nutrition in prenatal and early postnatal life resulted in increased age-associated enzymes in the liver and kidney [26] and it was first proposed in the 1970s that diet restriction in the early stages of life may be associated with accelerated aging [27].

One early study on mice showed that an alteration in diet shortly after birth sufficient to slow growth resulted in reduced lifespan [28]. This finding has recently been explored further. One study investigated the effect of prenatal exposure to a maternal low-protein diet on lifespan in rats [29]. Rat dams were fed either a 180-gram casein/kg control diet or a 90-gram casein/kg low-protein diet from conception until the end of pregnancy. The diets were balanced in energy content through the addition of carbohydrate to the low-protein diet. At delivery all rats were transferred to a non-purified chow diet and following weaning the offspring were maintained on this diet throughout life. The average lifespan of female rats exposed to low-protein diets in utero was reduced by 11\% (Fig. 1) [29]. There was a similar but non-significant trend in the male offspring. These findings are consistent with two other recent studies which found that prenatal diet restriction was associated with reduced lifespan [30, 31].

\section{Fetal and Infant Origins of Human Aging}

The effects of early dietary restriction on human aging are not known. However, a number of epidemiological studies have shown that markers of 


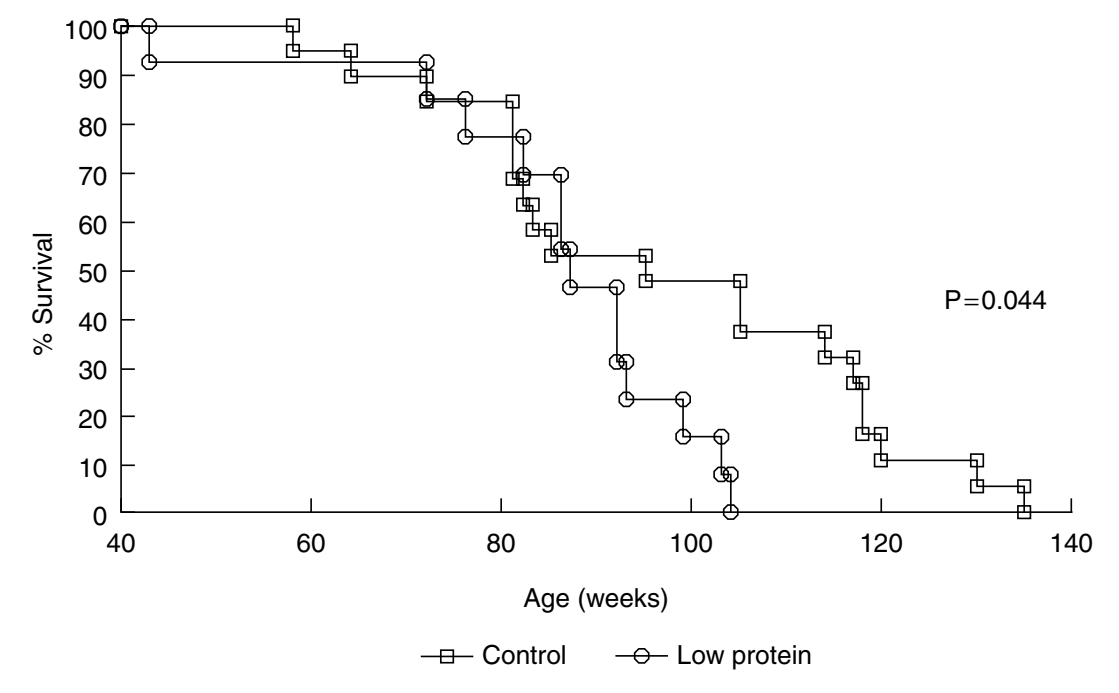

Fig. 1. Kaplan-Meier survival curves showing percentage survival of 19 control and 13 low-protein-exposed female rats up to the age of 135 weeks.

poor fetal growth, including low weight, thinness and shortness at birth, are associated with increased mortality and morbidity from cardiovascular disease and other age-related diseases [32]. These relationships hold true in men and women and are specific. For example, there is no relationship between birth weight and deaths from lung cancer [33]. Correlations have been shown between poor early growth and the major cardiovascular risk factors - raised blood pressure [34], raised plasma fibrinogen [35], and serum cholesterol concentrations [36], impaired glucose tolerance [37] and reduced arterial compliance [38]. Furthermore the people who were small in early life had a shorter lifespan. For example, among 10,000 British men and women, those who had below average birth weight and weighed less than $8.2 \mathrm{~kg}$ at 1 year had a 4-year lower life expectancy than those with above average birth weight who reached $12.25 \mathrm{~kg}$ at 1 year [33]. These associations have been replicated in several different countries including the United States [39], India [40] and China [41] as well as in Britain. As the major determinant of fetal growth is nutrition [8], the fetal origins hypothesis proposes that fetal undernutrition programs the long-term adverse sequelae of small size at birth. Support for human nutritional programming has come from a study showing that maternal diet in pregnancy influenced blood pressure in the adult offspring 40 years later [42]. 
Osteoporosis is another important age-related disease that has been associated with poor growth in early life. This is a skeletal disorder characterised by low bone mass and micro-architectural deterioration of bony tissue with a consequent increase in the risk of fracture [43]. The bone mass of an individual in later life depends upon the peak attained during skeletal growth, and the subsequent rate of bone loss. There is evidence to suggest that peak bone mass is inherited, but current genetic markers are able to explain only a small proportion of the variation in individual bone mass or fracture risk [44] and more recent research has demonstrated the importance of environmental influences acting during intrauterine and early postnatal life. One study of a cohort of men and women aged 65-75 years, born and still resident in Sheffield, has demonstrated a significant relationship between birth weight and adult bone mass (Fig. 2) [45]. These findings are consistent with results from two other British cohorts $[46,47]$ and a recent study showing that hip fracture was related to patterns of childhood growth [48]. Further evidence for the programming of osteoporosis comes from detailed physiological studies exploring the relationship between candidate endocrine systems that may be programmed (growth hormone - IGF-I; hypothalamic-pituitary adrenal, gonadal steroid) and age-related bone loss.

A recent epidemiological study has considered the relationship between poor early growth and aging changes in different body systems [49]. This was carried out in Hertfordshire, UK, where birth and infant records dating back to the early part of the last century were available. 1,428 men and women born between 1920 and 1930 with records of early weight were traced. Of these, 824 agreed to home interview by one of four nurses, and information on medical and social history, including smoking and drinking habits, was obtained. Social class was defined from occupation. After interview, 717 attended a local clinic for measurement of current size, grip strength, skin thickness, eye examination and a hearing test. Statistical analyses were used to quantify the relationship between birth weight, weight at 1 year, and each of the aging measures. Lower weight at 1 year was associated with reduced grip strength, thinner skin, increased lens opacity, and worse hearing (Table 1) [49]. The finding that lower adult grip strength was also associated with reduced birth weight was consistent with a study published this year showing that birth weight was significantly associated with adult muscle mass (Fig. 3) [45].

\section{Mechanisms for Nutritional Programming of Aging}

There is growing evidence that aging processes may be associated with nutrition and growth in early life. The mechanisms remain speculative. The aged phenotype may be viewed as the result of intrinsic and extrinsic 

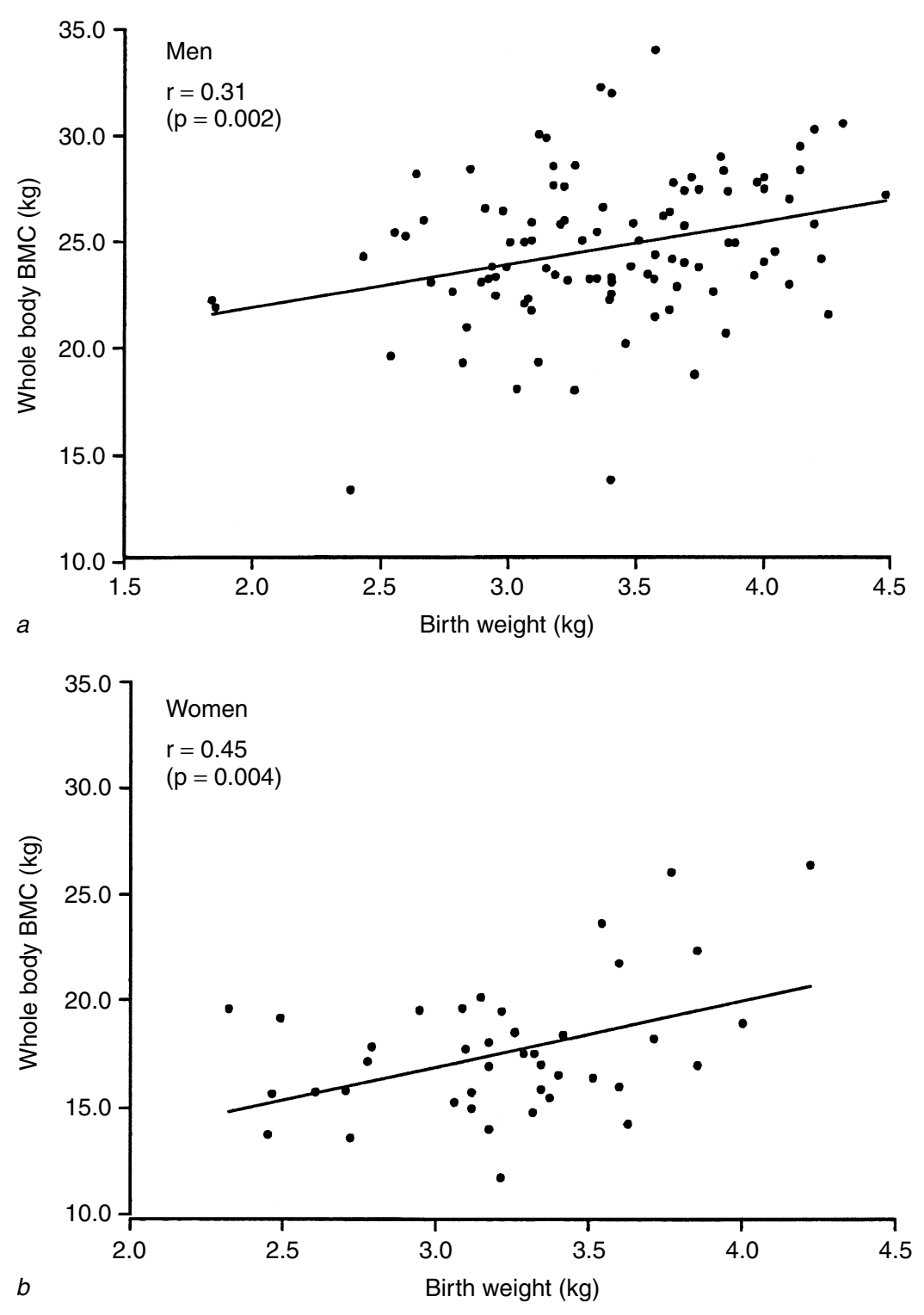

Fig. 2. The relationship between birth weight and whole body bone mineral content (BMC). 
Table 1. The association between early weights and age-related outcomes adjusted for age and sex

\begin{tabular}{|c|c|c|c|c|}
\hline \multirow[t]{2}{*}{ Early weight } & \multirow{2}{*}{$\begin{array}{l}\frac{1}{\text { Mean }} \\
\text { Lens opacity } \\
\text { score } \\
\text { (LOCS III) }^{\mathrm{a}}\end{array}$} & \multirow{2}{*}{$\begin{array}{l}\text { Aging } \\
\text { aring } \\
\text { eshold, }\end{array}$} & \multicolumn{2}{|l|}{ Outcome } \\
\hline & & & $\begin{array}{l}\text { Grip } \\
\text { strength } \\
\text { kg }\end{array}$ & $\begin{array}{l}\text { Skin } \\
\text { thickness } \\
\text { mm }\end{array}$ \\
\hline \multicolumn{5}{|l|}{ At birth, g [lb] } \\
\hline$\leq 2,500 \quad[\leq 5.5]$ & $.27(n=16)$ & $24.4(n=16)$ & $28.5(n=16)$ & $1.19(n=16)$ \\
\hline$-2,950[-6.5]$ & $36(n=94)$ & $29.3(n=93)$ & $30.3(n=$ & 1.27 \\
\hline$-3,400[-7.5]$ & $2.38(n=224)$ & $29.2(n=231)$ & $31.0(n=231)$ & $1.24(n=231)$ \\
\hline$-3,860[-8.5]$ & $2.38(n=205)$ & $28.7(n=217)$ & $32.2(n=217)$ & $1.24(n=217)$ \\
\hline$-4,310[-9.5]$ & $2.29(n=84)$ & $28.4(n=89)$ & $32.5(n=89)$ & $1.22(n=89)$ \\
\hline$>4,310[>9.5]$ & $2.36(n=32)$ & $28.8(n=35)$ & $32.4(n=$ & $1.25(n=3$ \\
\hline $\begin{array}{l}\text { Multiple } \\
\text { regression }\end{array}$ & $p=0.71$ & $p=0.97$ & $p=0.01$ & $p=0.32$ \\
\hline \multicolumn{5}{|l|}{ At 1 year, kg [lb] } \\
\hline$\leq 8.16 \quad[\leq 18]$ & $2.67(n=26)$ & $33.6(n=26)$ & $29.8(n=26)$ & $1.20(n=26)$ \\
\hline$-9.07 \quad[-20]$ & $2.40(n=133)$ & $29.4(n=134)$ & $30.7(n=134)$ & $1.22(n=134)$ \\
\hline$-9.98 \quad[-22]$ & $2.33(n=198)$ & $29.3(n=209)$ & $31.1(n=211)$ & $1.24(n=211)$ \\
\hline$-10.89[-24]$ & $2.37(n=187)$ & $29.1(n=194)$ & $31.6(n=194)$ & $1.25(n=194)$ \\
\hline$-11.79[-26]$ & $2.33(n=70)$ & $26.5(n=77)$ & $32.6(n=77)$ & $1.25(n=77)$ \\
\hline$>11.79 \quad[>26]$ & $2.24(n=41)$ & $24.8(n=41)$ & $34.2(n=41)$ & $1.25(n=41)$ \\
\hline \multicolumn{4}{|l|}{ Multiple } & $p=0.19$ \\
\hline & $2.36(n=655)$ & $28.8(n=681)$ & $31.5(n=683)$ & $1.24(n=$ \\
\hline Standard deviation & 1.21 & 1.6 & 10.1 & 0.18 \\
\hline
\end{tabular}

${ }^{\text {a }}$ Logarithms used in analysis are therefore geometric means.

${ }^{\mathrm{b}}$ Adjusted for age, sex, current social class, social class at birth and height.

exposures occurring from conception onwards and the corresponding response in terms of regeneration and repair. This has been called the lifelong exposure-response model of aging [50]. It follows that early nutrition may influence aging in a number of ways (Fig. 4) [50]. Early nutrition directly affects growth. This is mediated through endocrine factors released into the circulation and by paracrine peptide growth factors, such as IGFs acting locally. Undernutrition in fetal life may be associated with permanent stunting of growth [24] and can therefore affect aging by setting a lower peak from which age-related decline will occur. Nutrition in early life also affects the setting of a number of hormonal axes and early undernutrition is associated with long-term insulin resistance and higher circulating glucose levels [16]. Both proteins and nucleic acids are modified by reducing sugars in a process called non-enzymatic glycosylation. The extent of the modification is dependent on both the glucose concentration and length of exposure; a higher 

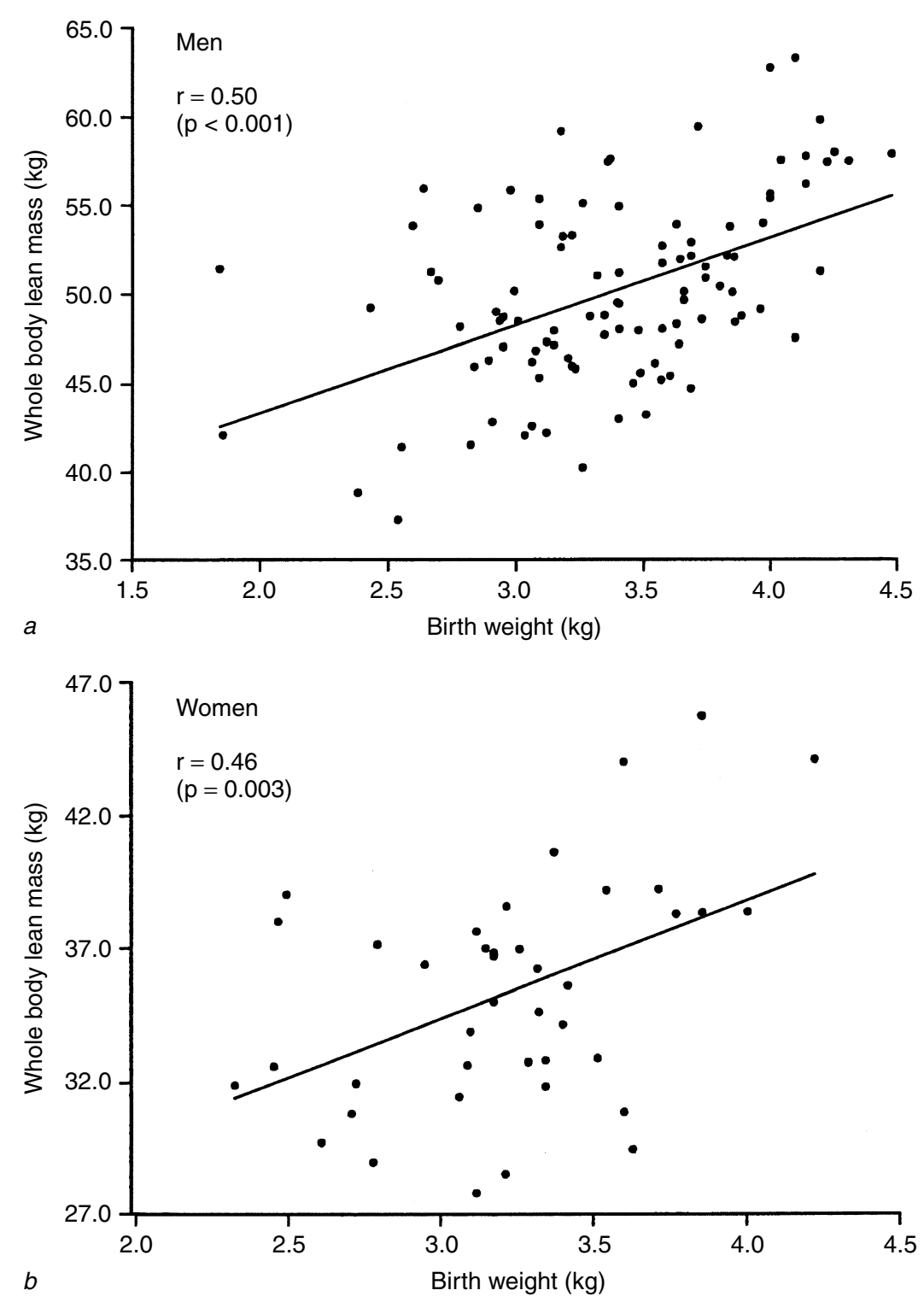

Fig. 3. The relationship between birth weight and whole body lean mass. 


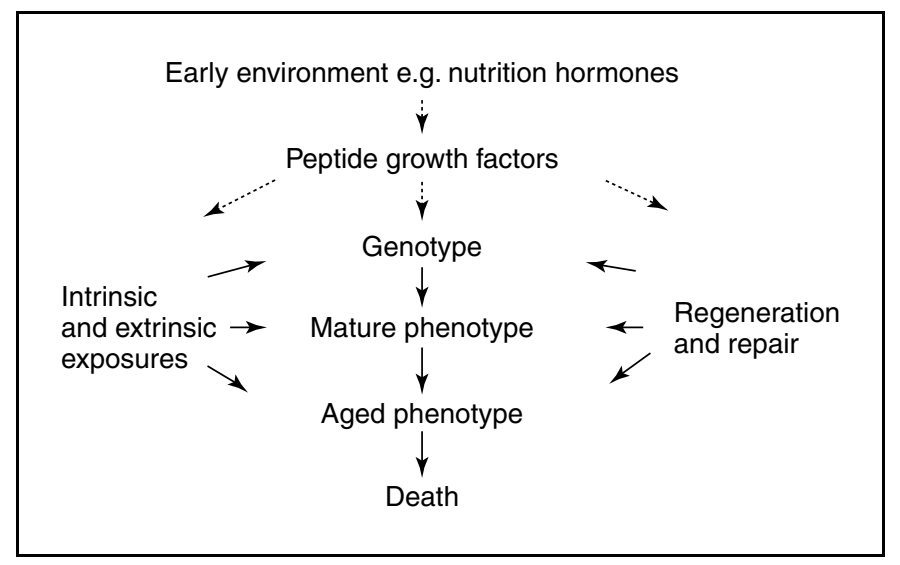

Fig. 4. Lifelong exposure-response model of aging illustrating potential mechanisms for the influence of early nutrition on subsequent aging.

glucose concentration and extended exposure lead to the formation of larger amounts of glycosylation end-products. This process is of particular relevance to long-lived molecules and is associated with altered function as well as structure [51]. It has been proposed that such changes are relevant to aging as well as diabetes in causing features such as increased atherosclerosis, cataracts and cross-linkage of collagen.

The ability to respond to deleterious exposures is increasingly being recognised as an important determinant of aging. The responses include repair and replacement of damaged molecules and cells. The disposable soma theory proposes that the avoidance of aging with perfect repair and regeneration processes does not occur because the energy requirements would jeopardise reproduction and therefore not be of evolutionary benefit [52]. There is some evidence that both repair and regeneration are maximal in embryonic and fetal life. At this early stage, these processes are regulated by peptide growth factors, which are widely synthesised and act within the local tissue environment. The IGFs and transforming growth factors are thought to be of prime importance in cellular maintenance [53]. Many cells continue to express growth factors even after differentiation, suggesting that growth factors continue to be involved in cell function in later life. There is some evidence that chronic early undernutrition permanently reduces IGF production [54] and this may be a further mechanism by which prenatal and early postnatal undernutrition have long-term effects on aging.

The programming of repair processes is likely to be most important in systems in which there is little turnover. This may explain the findings 
in the Hertfordshire study described earlier where the systems in which aging changes were related to early growth shared the feature of having a high proportion of long-lived molecules and cells. For example, the lens contains crystallins that, once formed are never turned over [55]. They are synthesised in the outer cortex of the lens and gradually move to the centre as new crystallins are formed. The centre of an adult lens therefore contains molecules formed in utero and maintenance processes through life are essential to maintain integrity. The cochlea of the ear contains long-lived collagen molecules and hair cells that, like brain cells, are not replaced [56], and muscle and skin contain large amounts of collagen as well as elastin, which undergo slow turnover. At present, the mechanisms for the nutritional programming of aging remain speculative. However, work is underway to investigate molecular repair mechanisms and their relationship to early growth and nutrition. Markers of DNA repair capacity including telomere length will be measured in a large molecular epidemiological study based in Hertfordshire.

\section{Conclusions}

Animal intervention studies and human observational studies provide growing evidence for the influence of the early environment on aging in later life. This may be explained by environmental programming whereby a stimulus or insult acting at critical periods of growth and development has lasting or lifelong effects. Inadequate nutrition and poor growth in early life are associated with a reduction in lifespan, an increased incidence of a number of age-related diseases and greater structural and functional changes associated with age. The underlying mechanisms remain speculative but may include a permanent reduction in size, resetting of hormonal axes and the impaired development of repair process.

\section{References}

1. Dubos R, Savage D, Schaedler R. Biological freudianism. Lasting effects of early environmental influences. Pediatrics 1966; 38: 789-800.

2. Deeming DC, Ferguson MWJ. Physiological effects of incubation temperature on embryonic development in reptiles and birds. In Deeming DC, Ferguson MWJ, eds. Egg incubation: its effects on embryonic development in birds and reptiles. Cambridge: Cambridge University Press, $1991 ; 147-71$.

3. Blakemore C. Sensitive and vulnerable periods in the development of the visual system. Ciba Found Symp 1991; 156: 129-54.

4. LaLande NM, Hetu R, Lambert J. Is occupational noise exposure during pregnancy a risk factor of damage to the auditory system of the fetus? Am J Ind Med 1986; 10: 427-35.

5. Dunn DE, Lim DJ, Ferraro JA. Effects on the auditory system from in utero noise exposure in lambs [abstract]. Assoc Res Otolaryngol 1981; 61: 20. 
6. Saunders JC, Bock GR. Influences of early auditory trauma on auditory development. In: Gottlieb G ed. Studies on the development of behaviour and the nervous system. New York: Academic Press, 1978; 249-87.

7. Lavigne-Rebillard M, Pujol R. Hair-cell innervation in the fetal human cochlea. Acta Otolaryngol 1988; 105: 398-402.

8. Gluckman P, Harding JE. The regulation of fetal growth. In: Hernandez M, Argente J, eds. Human growth: basic and clinical aspects. Amsterdam: Excerpta Medica, 1992; 253-60.

9. Snow MHL. Effect of genome on size at birth. In: Sharp F, Fraser RB, Milner RDG, eds. Fetal growth. London: Royal College of Obstetricians and Gynaecologists, 1989; 3-12.

10 Widdowson EM, McCance RA. A review: new thoughts on growth. Pediatr Res 1975; 9: $154-6$.

11. Steegmann AT, Jr. 18th century British military stature: growth cessation, selective recruiting, secular trends, nutrition at birth, cold and occupation. Hum Biol 1985; 57: 77-95.

12. Ravelli G-P, Stein ZA, Susser MW. Obesity in young men after famine exposure in utero and early infancy. $N$ Engl $J$ Med 1976; 295: 349-53.

13. Dorner G. Environment-dependent brain differentiation and fundamental processes of life. Acta Biol Med Germ 1974; 33: 129-48.

14. Harding JE: Fetal nutrition and growth. Int J Diab Dev Countries 2001; 21: 9-11.

15. Snoeck A, Remacle C, Reusens B, Hoet JJ. Effect of a low protein diet during pregnancy on the fetal rat endocrine pancreas. Biol Neonate 1990; 57: 107-18.

16. Petry CJ, Ozanne SE, Wang CL, Hales CN. Effects of early protein restriction and adult obesity on rat pancreatic hormone content and glucose tolerance. Horm Metab Res 2000; 32: 233-9.

17. Winick M, Rosso P, Brasel JA. Malnutrition and cellular growth in the brain: existence of critical periods. Ciba Found Symp 1972; 199-212.

18. Birch E, Birch D, Hoffman D, Hale L, Everett M, Uauy R. Breast-feeding and optimal visual development. J Pediatr Ophthalmol Strabismus 1993; 30: 33-8.

19. Matsui R, Thurlbeck WM, Fujita Y, Yu SY, Kida K. Connective tissue, mechanical and morphometric changes in the lungs of weanling rats fed a low protein diet. Pediatr Pulmonol 1989; 7: 159-66.

20. Zeman FJ. Effects of maternal protein restriction on the kidney of the newborn young of rats. J Nutr 1968; 94: 111-6.

21. Langley SC, Jackson AA. Increased systolic blood pressure in adult rats induced by fetal exposure to maternal low protein diets. Clin Sci 1994; 86: 217-22.

22. Schrader RE, Zeman FJ. Effect of maternal protein deprivation on morphological and enzymatic development of neonatal rat tissue. J Nutr 1969; 99: 401-21.

23. Aihie Sayer A, Cooper C. Undernutrition and aging. Gerontology 1997; 43: 203-5.

24. Chow BF, Lee C-J. Effect of dietary restriction of pregnant rats on body weight gain of the offspring. J Nutr 1964; 82: 10-8.

25. Kahn AJ. Embryogenic effect on post-natal changes in hemoglobin concentration with time. Growth 1968; 32: 13-22.

26. Roeder LM. Effect of the level of nutrition on rates of cell proliferation and of RNA and protein synthesis in the rat. Nutr Rep Int 1973; 7: 271-88.

27. Roeder LM, Chow BF. Maternal undernutrition and its long-term effects on the offspring. Am J Clin Nutr 1972; 25: 812-21.

28. Brailsford Robertson T, Ray LA. On the growth of relatively long lived compared with that of relatively short lived animals. J Biol Chem 1920; 42: 71-7.

29. Aihie Sayer A, Dunn R, Langley-Evans S, Cooper C. Prenatal exposure to a maternal low protein diet shortens lifespan in rats. Gerontology 2001; 47: 9-14.

30. Jennings BJ, Ozanne SE, Dorling MW, Hales CN. Early growth determines longevity in male rats and may be related to telomere shortening in the kidney. FEBS Lett 1999; 448: 4-8.

31. Vehaskari VM, Aviles DH, Manning J. Prenatal programming of adult hypertension in the rat. Kidney Int 2001; 59: 238-45.

32. Barker DJP. Mothers, babies and health in later life. Edinburgh: Churchill Livingstone, 1998.

33. Osmond C, Barker DJP, Winter PD, Fall CHD, Simmonds SJ. Early growth and death from cardiovascular disease in women. BMJ 1993; 307: 1519-24.

34. Barker DJP, Osmond C, Golding J, Kuh D, Wadsworth MEJ. Growth in utero, blood pressure in childhood and adult life, and mortality from cardiovascular disease. BMJ 1989; 298: 564-7. 
35. Barker DJP, Meade TW, Fall CHD, Lee A, Osmond C, Phipps K, et al. Relation of fetal and infant growth to plasma fibrinogen and factor VII concentrations in adult life. BMJ 1992; 304: 148-52.

36. Fall CHD, Barker DJP, Osmond C, Winter PD, Clark PMS, Hales CN. Relation of infant feeding to adult serum cholesterol concentration and death from ischaemic heart disease. BMJ 1992; 304: $801-5$.

37. Hales CN, Barker DJP, Clark PMS, Cox C, Fall C, Osmond C, et al. Fetal and infant growth and impaired glucose tolerance at age 64 years. BMJ 1991; 303: 1019-22.

38. Martyn CN, Barker DJP, Jesperson S, Greenwald S, Osmond C, Berry C. Growth in utero, adult blood pressure and arterial compliance. Br Heart J 1995; 73: 116-21.

39. Rich-Edwards JW, Stampfer MJ, Manson JE, Rosner B, Hankinson SE, Colditz GA, et al. Birth weight and risk of cardiovascular disease in a cohort of women followed up since 1976. BMJ 1997; 315: 396-400.

40. Stein CE, Fall CH, Kumaran K, Osmond C, Cox V, Barker DJ. Fetal growth and coronary heart disease in south India. Lancet 1996; 348: 1269-73.

41. Mi J, Law C, Zhang KL, Osmond C, Stein C, Barker D: Effects of infant birthweight and maternal body mass index in pregnancy on components of the insulin resistance syndrome in China. Ann Intern Med 2000; 132: 253-60.

42. Campbell DM, Hall MH, Barker DJP, Cross J, Shiell AW, Godfrey KM. Diet in pregnancy and the offspring's blood pressure 40 years later. Br J Obstet Gynaecol 1996; 103: 273-80.

43. Cooper C, Aihie A. Osteoporosis: recent advances in pathogenesis and treatment. $Q \mathrm{~J} \mathrm{Med}$ 1994; 87: 203-9.

44. Ralston SH. Do genetic markers aid in risk assessment? Osteoporos Int 1998; 8 (Suppl 1): S37-42.

45. Gale CR, Martyn CN, Kellingray S, Eastell R, Cooper C. Intrauterine programming of adult body composition. J Clin EndocrinolMetab 2001; 86: 267-72.

46. Cooper C, Cawley M, Bhalla A, Egger P, Ring F, Morton L, et al. Childhood growth, physical activity, and peak bone mass in women. J Bone Miner Res 1995; 10: 940-7.

47. Cooper C, Fall C, Egger P, Hobbs R, Eastell R, Barker D. Growth in infancy and bone mass in later life. Ann Rheum Dis 1997; 56: 17-21.

48. Cooper C, Eriksson JG, Forsen T, Osmond C, Tuomilehto J, Barker DJP. Maternal height, childhood growth and risk of hip fracture in later life: a longitudinal study. Osteoporos Int 2001 ; in press.

49. Aihie Sayer A, Cooper C, Evans JR, Rauf A, Wormald RPL, Osmond C, et al. Are rates of ageing determined in utero? Age Ageing 1998; 27: 579-83.

50. Aihie Sayer A, Cooper C. Early undernutrition: good or bad for longevity? In: Watson RR, ed. Handbook of nutrition in the aged. Boca Raton: CRC Press, 2000; 97-106.

51. Lee AT, Cerami A. Modifications of proteins and nucleic acids by reducing sugars: possible role in aging. In: Schneider EL, Rowe JW, eds. Handbook of the biology of aging. San Diego: Academic Press, 1990; 116-30.

52. Kirkwood TBL, Wolff SP. The biological basis of ageing. The Medical Research Council/ Research into Ageing Workshop, 6 October 1993. Age Ageing 1995; 24: 167-71.

53. Han VKM, Fowden AL. Paracrine regulation of fetal growth. In: Ward RHT, Smith SK, Donnai D, eds. Early fetal growth and development. London: RCOG Press, 1994; 275-91.

54. Owens JA. Endocrine and substrate control of fetal growth: placental and maternal influences and insulin-like growth factors. Reprod Fertil Dev 1991; 3: 501-17.

55. Harding J. Cataract biochemistry, epidemiology and pharmacology. London: Chapman \& Hall, 1991.

56. NIH Consensus Development Conference. Noise and hearing loss. Washington: NIH, 1990.

\section{Discussion}

Dr. Roberts: In the epidemiological relations that you showed you used birth weight or weight at 1 year as opposed to BMI or height. How different are the results when you use BMI or height? 
Dr. Aihie Sayer: The early measures we used in this study were determined by the cohort. They were cohort-specific, depending on what had been recorded historically in a particular group of subjects. The Hertfordshire studies had results for both birth weight and weight at 1 year, so we could look at size in terms of weight, but we could not calculate BMI because we did not have length at birth. There are data sets available that include birth length - for example, in the Preston data we were able to look at BMI at birth and the effects were very similar to birth weight.

Dr. Roberts: In your Southampton study you have measured length, I know. But in those cases where weight is used as a surrogate for height or length, one assumes it is a surrogate for fatness as well, but it may not be.

Dr. Meydani: Have there been studies that have separated undernutrition from energy restriction in very early life and examined the effects on later outcomes?

Dr. Aihie Sayer: As far as I understand it, the literature on preweaning diet restriction in animals is very sketchy. The interventions that have been applied in the postweaning diet restriction model do not exist in the preweaning model.

Dr. Rosenberg: I am interested in the effect of early nutritional exposure on later insulin sensitivity and resistance. I know that Yajnick has shown that low birth weight is associated with evidence of insulin resistance even early in life at age 4 or so [1]. Could you comment on how the Southampton group is now looking at the evolution of these effects later in life?

Dr. Aihie Sayer: There have been several convincing studies now from different groups looking at the regulation of insulin and glucose metabolism. Small size at birth in humans is certainly associated with impaired glucose tolerance in later life, related to insulin resistance and maybe also to insulin deficiency [2]. That study has been replicated many times. From animal models, there is evidence of changes in the pancreatic islet cells with reduced vascularization, reduced levels of insulin, and correspondingly higher levels of glucose. One could postulate that this might well have effects later in life. If there is permanent resetting of that axis, then exposure to raised levels of glucose, for example, would constitute an increased internal source of damage from glycation products.

Dr. Burckhardt: You showed that in certain studies birth weight plays a different role from weight at age 1 year - thus the situation changes. This means that birth weight is one thing and what happens in the first year of life has other implications. Nutrition during the first year is the mother's affair and not the baby's - it is not an ad libitum situation. So my question is, do you have any data which show that the birth weight of the baby influences the behavior of the mother? Does the mother of an underweight baby behave differently in giving food to her baby than a mother of a normal weight baby?

Dr. Aihie Sayer: That's a good question. You might imagine that that would be the case, and that an underweight baby would get increased feeding during the first year of life. I certainly think that is possible. Though we don't have data on that at present, we will have this information prospectively as part of the Southampton women's survey. It is worth emphasizing that the birth weights I'm talking about fall within the normal range. We are not talking about low birth weight; we are talking about weights which would not of themselves create concern. Also these data are from the early part of the 20th century when very small babies rarely survived. It seems unlikely that there were many surviving neonates at that time who were small enough to change their mothers' behavior dramatically, although we can't test that. The issue about birth weight versus weight at 1 year is interesting. We sometimes see an effect with birth weight, sometimes with weight at 1 year, sometimes with both. You are right to emphasize that weight at 1 year is about postnatal nutrition and what the 
mother does, but there is also some evidence that weight at 1 year is related to late gestation and to the growth trajectory set up at that stage.

Dr. Serrano Ríos: Do you have data on insulin-like growth factor and leptin concentrations in the umbilical vein in low birth weight babies, compared with normalsized babies? We have data showing that leptin levels in the umbilical vein at birth may be predictive of the future metabolic utilization of substrate. There are also studies from Hoet and his Belgian group showing that organogenesis of the pancreas - not only the endocrine pancreas but the exocrine pancreas as well - is greatly impaired when rats are given a low protein diet during the period of gestation [3]. I would like your comments please.

Dr. Aihie Sayer: Hoet has done wonderful work, showing dramatic effects on the pancreas and pancreatic function with a maternal early diet model. Your question about leptin is interesting. Though we haven't got results yet, David Phillips in Southampton is currently looking at leptin levels in a cohort of individuals for whom we have early growth data. You also asked about growth factors. We have looked at insulin-like growth factor levels in relation to birth size and we are now going on to look at adult growth factor levels. The growth hormone axis is difficult to study, as the levels fluctuate and there is a circadian cycle. We are working on how best to allow for these variations.

Dr. Payette: With respect to birth weight and weight at 1 year, one way to look at that would be to do a correlation analysis between those variables. Did you do that?

Dr. Aihie Sayer: Yes, we have. Birth weight and weight at 1 year are highly correlated - the larger you are at birth, the larger you are at 1 year. You can put both into a regression model and see which one is having the most effect. In the Hertfordshire cohort it was generally weight at 1 year, but in other data sets both had a similar effect in the regression model.

Dr. Hirsch: Do you know if there are differences between the babies depending on whether they are breast-fed or bottle-fed?

Dr. Aihie Sayer: We do have limited information on whether the babies were breastfed or bottle-fed, but unfortunately it is not complete enough to allow any conclusions to be drawn. We are in the process of collecting this information prospectively.

Dr. Rosenberg: There is a great deal of interest in how much of the variance in later health effects can be predicted by these early life measures. You have a huge amount of data on this from your studies in Southampton and from other studies. Are you prepared to make any judgments about the percentage of the variance relating to cardiovascular disease, high blood pressure, insulin resistance, and so forth, at age 50 and beyond, that might be entrained by these early life effects, either birth weight or weight at 1 year?

Dr. Aihie Sayer: If you look at the amount of the variance that is explained by known risk factors, it is small - both with respect to traditional adult risk factors and the early life ones. The size of effect of the early life factors is comparable with that of the traditional factors, but the proportion of the total amount of variance is still small. We need mortality data to work out how much of the absolute risk is accounted for by the early life data. The people who were recorded in the ledgers are dying now - they are in their 70s - and we are collecting the data. We will be able to answer this question much better when we have a larger number of deaths within the group.

Dr. Roberts: There are quite major differences in formulas which may be interesting to analyze for long-time effects. For example the Nestlé Carnation formula is marketed as a 'standard' formula, but in terms of its composition it is quite different from what used to be marketed as a traditional formula. So it will be important to look 
at the differences within formulas as well as between breast feeding and formula feeding.

Dr. Aihie Sayer: I agree. We really don't know what formula milks were being fed in the 1920s. The current prospective study will allow us to compare different types of early formula diets.

Dr. Endres: As formulas tend to change every 2 or 3 years it may be difficult to analyze their effects in the long term, though I agree it would be very interesting. One recent paper about long-term outcome that is relevant to this discussion was by Lucas [4], who showed that those infants who had been breast fed for only for 4 weeks had a lower blood pressure in adolescence than formula-fed infants. In the short-term, it is also known that breast feeding appears to lead to better intelligence at 8-9 years of age [5].

Dr. Serrano Ríos: Do you have information about individuals who were supposed to have had fetal undernutrition and who continued to be undernourished after birth, in comparison with those who caught up and were no longer considered malnourished? It is very striking how the insulin resistance syndrome, with metabolic changes, is now becoming as prevalent in developing countries as in the developed countries, once you have adjusted for lifestyle changes. Presumably people in developing countries are at higher risk of developing undernutrition during fetal life. So to what extent do you think that postnatal nutritional status can influence the likelihood of these individuals developing cardiovascular disease in adult life? I think this has very important implications in many countries.

Dr. Aihie Sayer: Of course, with the human data we haven't got nutritional data in most of the studies. What we have is a proxy with small size, and we haven't got prospective information on size until adulthood. But your point on the developing world is very valid. You are absolutely right - the prevalence of impaired glucose tolerance is shooting up in places like India. There is evidence there of a strong association between small size at birth, presumably related to undernutrition at that stage, and the high rates of impaired glucose tolerance in later life [6]. What the right form of nutrition should be after undernutrition in early life is the six million dollar question. There is evidence that overnutrition later in life has an additive effect to poor nutrition early on, so there is a lot to look at there.

Dr. Meydani: There have been some recent studies [7] showing that exposure during fetal life to high cholesterol diets increases the risk of cardiovascular disease, so it seems that nutritional status during fetal development is important, at least as far as cardiovascular disease is concerned.

Dr. Ferry: Do you think that a low protein diet during pregnancy, which has consequences for the pancreas, may increase susceptibility to disease in old age? We know that a low protein diet in old people can have dramatic consequences for pancreatic function.

Dr. Aihie Sayer: Malnutrition in old age is a major risk factor for pathology in all the systems, so that would fit into the general picture.

Dr. Arnaud: I am aware of a study showing that dehydration during pregnancy increases the appetite for salt in the newborn infant [8]. A higher sodium intake may also influence the development of cardiovascular disease, so the link may not only be with nutrition. Dehydration may be important too.

Dr. Aihie Sayer: I don't know that study, but it reinforces the fact that maternal diet and nutrition have profound influences and can affect the balance of many things. It is a challenge to determine what the most important factors that cause long-term sequelae are.

Dr. Taylor: Cataract incidence in India is increasing. Do you think there is a link with the low birth weight/impaired glucose tolerance problem you outlined earlier? 
Dr. Aihie Sayer: The prevalence of impaired glucose tolerance is rising steeply in India, and we have shown from several studies in different Indian populations that low birth size is associated with impaired glucose tolerance in early and later adult life. We haven't looked at cataract but you could imagine that high glucose levels, diabetic status, and cataracts are likely to be closely linked.

\section{References}

1. Yajnik CS, Fall CHD, Vaidya U, Pandit AN, Bavdekar A, Bhat DS, Osmond C, Hales CN, Barker DJP. Fetal growth and glucose and insulin metabolism in four-year-old Indian children. Diab Med 1995; 12: 330-336.

2. Phillips DIW. Insulin resistance as a programmed response to fetal undernutrition. Diabetologia 1996; 39: 1119-1122.

3. Snoeck A, Remacle C, Reusens B, Hoet JJ. Effect of a low protein diet during pregnancy on the fetal rat endocrine pancreas. Biol Neonate 1990; 57: 107-118.

4. Singhal A, Cole TJ, Lucas A. Early nutrition in preterm infants and later blood pressure: two cohorts after randomised trials. Lancet 2001; 357: 413-419.

5. Horwood LJ, Darlow BA, Mogridge N. Breast milk feeding and cognitive ability at 7-8 years. Arch Dis Child Fetal Neonatal Ed 2001; 84: F23-7.

6. Fall $\mathrm{CH}$, Barker DJ. The fetal origins of coronary heart disease and non-insulin dependent diabetes in India. Indian Pediatr 1997; 34: 5-8.

7. Napoli C, Glass CK, Witztum JL, Deutsch R, D’Armiento FP, Palinski W. Influence of maternal hypercholestrolaemia during pregnancy on progression of early atherosclerotic lesions in childhood: fate of early lesions in children (FELIC) study. Lancet 1999; 354: 1234-41.

8. Nicolaïdis S, Galaverna O, Metzler C. Extracellular dehydration during pregnancy increases salt appetite of offspring. Am J Physiol-Reg Int Comp Physiol 1990; 258; (27): R281-R283. 